\title{
Modelos e análises computacionais em neurociências: revisão sistemática
}

\section{Computational models and analyses in neuroscience: systematic review}

\author{
Álvaro Machado Dias* \\ Pós-doutorando do Instituto de Psiquiatria da Universidade de São Paulo - IPq- \\ FMUSP, São Paulo, SP, Brasil
}

\begin{abstract}
RESUMO
Os modelos computacionais do cérebro humano podem ser classificados em 'modelos para tratamento de dados' (i.e. mapas de coordenadas cerebrais) e 'modelos de princípios operacionais' (modelos conexionistas). A literatura relativa a ambos é vasta e muito variada, o que dificulta a realização de revisões sistemáticas. O objetivo do presente artigo é contribuir para o suprimento desta demanda e fornecer uma visão dos desenvolvimentos mais interessantes em andamento. Método: além dos métodos tradicionais de revisão, foi utilizado um programa para reconhecimento e quantificação de padrões em sistemas complexos (i.e. genomas). Resultados: entre os 2749 estudos do campo, aprendizado e memória são os tópicos mais recorrente, modelados em 0.14 e 0.9 dos estudos; Epilepsia, esquizofrenia e Parkinson são as doenças mais modeladas computacionalmente; Alzheimer é a quarta, sendo por sua vez mais relacionada à MRI $(r=0.5435)$ do que à MEG $(r=0.2033)$, PET $(r=0.4718)$ e EEG $(r=0.1766)$. Entre os 87 estudos 2007-2009 em 'modelos de princípios operacionais', o conceito mais proeminente é o de arquiteturas de pequenos mundos. O projeto mais excitante em desenvolvimento é o Blue Brain Project, que objetiva a criação de um modelo computacional do cérebro todo.

Palavras-chave: Modelos computacionais, Cérebro humano, Neuroanatomia, Neurofisiologia, Revisão sistemática.
\end{abstract}

\begin{abstract}
Computational models of the human brain may be classified as 'data treatment models' (brain maps) and 'operational-inspired models' (connectionist models). The literature on both is extensive and varied, rendering difficulties to systematic reviews. This paper aims to contribute to outfit such demand, and to provide an overview of the most exciting projects currently under development. Method: besides traditional revising methods, a data mining program used to acknowledge patterns in complex databases (e.g. genomes) was used. Results: among the 2749 studies, learning and memory were the most recurrent topics, modeled in 0.14 and 0.9 of the studies. Epilepsy, schizophrenia and Parkinson are the most computationally simulated diseases; Alzheimer is the fourth, and more correlated to MRI $(r=0.5435)$ than to MEG $9 r=0.2033)$, PET $(r=0.4718)$ and EEG $(r=0.1766)$. Among the 87 2007-2009 studies on 'operational-inspired
\end{abstract}


models', small world architectures is the most prominent concept. The most exciting project under development is the Blue Brain Project, which aims to provide a computational model of the whole brain.

Keywords: Computational models, Human brain, Neuroanatomy, Neurophysiology, Systematic review.

\section{I ntrodução}

Sem desconsiderar a pletora de esforços e avanços que mantém, desde tempos imemoriais, a compreensão do funcionamento da mente humana entre as mais elevadas aspirações epistemológicas da humanidade, é de se considerar que uma verdadeira ruptura de paradigmas tenha se dado pela iniciativa de descrevê-la à luz do funcionamento do computador digital.

A seara aberta pela pioneira investida de Turing (1950), apenas cinco anos após o primeiro esboço técnico sobre o possível funcionamento de um sistema digital (VON NEUMANN, 1945), expandiu os limites epistemológicos até então convencionados aos estudos da mente, fazendo com que este campo se tornasse crescentemente aberto às empreitadas multidisciplinares, o que por sua vez representou a pedra de toque para a consolidação do campo das ciências cognitivas (para uma introdução histórica aos modelos computacionais da mente/cérebro e sua inserção na Teoria do Conhecimento, ver: GOLDSTINE, 1972).

Dito isto, faz-se também considerável a perda de prestígio que sofreu a abordagem computacional à mente/cérebro (doravante 'cérebro') desde o final da década de 1980, em relação à qual, destacam-se como responsáveis alguns setores do campo que a acusaram de não preservar o 'meio ambiente humanista', ao confundir sintaxe e semântica (SEARLE, 1990) e ao implicar o conceito de implementação biológica com a operação de símbolos. Em particular, este último aspecto foi considerado pela comunidade científica main stream como incompatível com uma série de perspectivas pouco questionáveis, tais como o princípio da degradação suave, isto é, o lento e peculiar desmantelo que sofrem as habilidades cognitivas em função da morte dos neurônios que lhes são determinantes, ao contrário do que ocorre em meio digital onde impera a 'degradação catastrófica', desde a corrupção de algumas poucas células binárias (para discussões famosas deste ponto, ver: CHURCHLAND, 1986; JOHNSON-LAIRD, 1988; MARCUS, 2001).

Mormente, justamente da crítica a esta concepção simbólica (a qual naturalmente implica uma sintaxe e assim o serialismo) fez-se o prestígio da modelagem conexionista, a qual ainda durante a década de 1980 despontava como a mais forte tendência no campo (para clássicos nesta discussão, ver: MIRA, 2008; SMOLENSKY, 1988). 
O conexionismo, conjunto de abordagens ao funcionamento de sistemas inteligentes baseado na concepção de que o comportamento complexo deve ser modelado pela atuação de elementos de grande simplicidade individual associados em redes complexas, tornou-se 0 motor da criação de vários modelos endereçados a desempenhos específicos, geralmente sob o princípio de que a qualidade de um modelo estaria diretamente relacionada à complexidade das tarefas que poderia executar em função de um número mínimo de regras.

O foco destas modelagens é a caracterização de 'fluxos autoreguladores', isto é, sistemas dinâmicos (que tal como um fluxo não podem ser descritos ponto a ponto) capazes de aprender com a experiência, sob a máxima de que o aprendizado é correlato da plasticidade do sistema e, em sua infraestrutura, materialmente representável por alterações seletivas na facilidade com que determinadas retransmissões devem ocorrer ao longo da cadeia.

Paralelamente, é de se ter em vista que o rechaço à inspiração computacional original tanto mais simbólica e menos preocupada com este caráter plástico, não tenha sido apenas técnica, mas reflexa do zeitgeist de uma época em que floresciam tanto os estudos de psicologia de caráter behaviorista (críticos à excessiva préprogramação), quanto os estudos de filosofia de inspiração pósmodernista (críticos à centralidade 'metafísica').

Sob esta chave, a ciência cognitiva da modelagem do cérebro seguiu sem pecha o seu curso acelerado, tal como se a redução à metáfora e às limitações algorítmicas das máquinas digitais, não mais representasse um entrave epistemológico. Muito pouco se discutiu e tanto menos se circunscreveu ao plano dos entraves que produziram a derrocada do cognitivismo de inspiração digital, o fato de que nenhuma evidência direta do modo de funcionamento do cérebro tenha sido jamais delineada, sem contar com uma interface digital.

Contrariamente a este simplismo, é mister considerar que se o cérebro é irredutível aos princípios digitais originais, ele tão pouco se adéqua aos dispositivos derradeiramente responsáveis pela coroação da década de 1990 como a 'década do cérebro': os modelos computacionais que determinam 'achados' em ressonâncias magnéticas funcionais, QEEG/Lorettas (respectivamente, eletroencefalografias quantitativas e mapeamento tridimensional eletroencefalográfico); tractografias por difusão de tensão (DTI) (análise da conectividade entre áreas do cérebro através de imageamento e algoritmo para o comportamento das moléculas de água em torno dos feixes axônicos) e outros métodos afins.

Apenas para dar uma dimensão deste viés na realidade prática, consideremos o caso da ressonância magnética funcional (fMRI, imageamento da perfusão sanguínea sensível ao tempo): uma tendência atual no domínio dos estudos de revisão em ciência cognitiva é a realização de metas-análise de fMRI, no intuito de 
associar, voxel a voxel, áreas cerebrais a desempenhos (para exemplos em destaque, ver: KOBER; BARRETT; JOSEPH; BLISSMOREAU; LINDQUIST; WAGER, 2008; LEE; SIEGLE, 2009; MAISOG; EINBINDER; FLOWERS; TURKELTAUB; EDEN, 2008; RICHLAN; KRONBICHLER; WIMMER, 2009; LAIRD; ROSENBLOOM; NEWELL; SOAR, 2008). Um destes estudos (WAGER; LINDQUIST; KAPLAN, 2007) apontou que, sob os mais conservadores paradigmas, cerca de $17 \%$ dos achados em imageamento funcional de áreas corticais relacionadas à memória de longo prazo poderiam ser considerados falsos positivos; como resumem os autores: "falsos positivos são endêmicos em pesquisas de imageamento funcional" (idem; p.151).

Em parte, este caso e outros decorrem de vieses metodológicos que poderiam ser contornados aumentando-se o número de sujeitos (N) e diminuindo-se o intervalo de confiança, ou então pela substituição do aparelho de ressonância por outro mais potente; porém, isto não oblitera o fato de que os achados variam tanto em função dos modelos computacionais utilizados (i.e. modelos de normalização espacial, modelos de análises de componentes), quanto em função das limitações inexoravelmente impostas pela linguagem computacional que conhecemos. Até porque, um 'achado' em fMRI não é algo que desponta imediatamente, mas sim o resultado de uma série de operações computacionais que visam separar informações de interesse de um sem fim de informações contingentes e artefatos.

É claro que alguém poderia afirmar que este é tão somente mais um caso a ser alinhavado sob o mote da irredutibilidade dos objetos às suas representações (dir-se-ia: um problema a ser tratado por Oscar Wilde e não pela comunidade científica). Não obstante, a relação entre fato e achado no âmbito da ciência cognitiva é bastante diversa daquela que se observa, por exemplo, entre os diversos telespectadores de uma novela televisiva (ou de um quadro figurativo), em que a trama se desenvolve sem que se faça problemática a possibilidade de que se confunda uma mulher com um chapéu (SACKS, 1997).

Assim, conforme desponta que os únicos modelos do funcionamento do cérebro com algum potencial ontológico são, por excelência, computacionais, as coisas se invertem para o legado da inspiração digital, o qual, diga-se de passagem, vêm sendo crescentemente resgatado na atualidade (O'REILLY; BRAVER; COHEN, 1999; O'REI LLY; RUDY, 2000).

Dito isto, permanece patente a diferença entre o conceito de modelo computacional que se faz aplicado à representação dos princípios operacionais do cérebro humano (dir-se-ia: a 'metáfora computacional') e o conceito de modelo computacional que perpassa o tratamento de dados direta (ressonância magnética) ou indiretamente (eletroencefalografia) relacionados à atividade cerebral. 
Considerando o que foi dito acima, a essência desta diferença não reside no 'potencial de verdade embutido nas diversas modelagens', mas no fato de que modelos voltados à representação operacional são simultaneamente executáveis e executores, enquanto modelos voltados para o processamento de dados são apenas executáveis. De outro modo: enquanto os modelos computacionais para tratamento de dados só produzem outputs pela alimentação do sistema com dados do tipo correto e a condução de rotinas pré-estabelecidas, os modelos computacionais que simulam partes do cérebro humano não aceitam alimentação de dados, mas implicam um output em tese correto conquanto precisamente trazem embutida a descrição da rotina implementada.

Denominemos os primeiros 'modelos computacionais no sentido fraco' (para um conjunto de exemplos típicos: THOMPSON; APOSTOLOVA, 2007) e os segundos, 'modelos computacionais no sentido forte' (para um exemplo típico: LAIRD; ROSENBLOOM; NEWELL; SOAR, 1986). Considerando estes dois tipos, o presente artigo se propõe a revisar sistematicamente a literatura em modelos computacionais do cérebro humano, em duas etapas: primeiramente contemplando ambos os tipos de modelos, ao longo de toda a história destas tradições; em seguida, contemplando os modelos computacionais em sentido forte, em um contexto histórico restrito (atualização).

\section{Método}

\section{Compilação dos dados}

A base de dados relativa à 'totalidade dos modelos computacionais' foi sistematizada desde a totalidade das publicações indexadas sob o tema no PubMed, resgatadas através do uso das seguintes palavraschave (computerized models of human brain NOT ("brain computer interface"); (computer models of human brain) NOT ("brain computer interface"); (computer simulation of human brain) NOT ("brain computer interface"); (computerized neural functioning); (digital simulation of human brain); e novamente todas as buscas substituindo 'brain' por 'cortex'. O critério de exclusão visou eliminar referências em neurofeedback e terapias afins cujo foco não é a modelagem computacional, mas o comportamento dos sujeitos/participantes. Estudos em animais foram incluídos desde que visassem indiretamente o funcionamento do cérebro humano, o que por sua vez foi definido por menções explícitas ao mesmo no título, resumo ou palavras-chave. Estes dados foram compilados em uma biblioteca de referências, da qual foram excluídas as referências repetidas e outras que apresentavam risco potencial de distorcerem a análise (i.e. artigos com o mesmo nome, publicados em periódicos diferentes; resumos de congressos sem identificadores completos).

A compilação dos dados para a análise dos modelos computacionais em sentido forte seguiu o mesmo plano geral, com as seguintes 
diferenças: as bases de dados utilizadas foram PubMed, ISI, Psycholnfo e OVID MedLine; referências pré-arquivadas de interesse foram acrescentadas; apenas artigos em periódicos foram considerados; apenas estudos diretamente implementados na modelagem do cérebro humano foram considerados (humanos 'em estrito senso'); o período de análise restringiu-se a 2007-2009.

\section{Análise dos Dados}

Para atingir seu objetivo maior, que é a sistematização da análise de uma vasta quantidade de dados em tão exíguo espaço, o presente artigo fez um uso inédito na literatura latino-americana de uma metodologia desenvolvida para a determinação e análise de padrões em sistemas complexos (i.e. genomas), através de data mining (para uma introdução, ver: YANG; AKERS; KLOSE; BARCELON , 2008; para exemplos aplicados, ver: DAY; ARNOLD; HODKINSON; LOVESTONE; BARNES, 2008; GEYER; EDDY, 2008). Este recurso permitiu a circunscrição dos principais vetores do campo de maneira quantitativamente fundamentada, culminando na apresentação de correlações entre conceitos de interesse, de modo a desvelar realidades até então ocultas sob o manto da literatura.

Paralelamente, a revisão das publicações recentes em modelos computacionais no sentido forte, contou com uma seção introdutória aos fundamentos atuais do campo, uma tabulação manual dos artigos (resgatados e discernidos em sua totalidade), uma matriz de correlação entre os conceitos mais significativos e, finalmente, uma apresentação breve (porém relativamente densa) de um dos tópicos tabulados mais significativos para se compreender o desenvolvimento das pesquisas atuais.

\section{Resultados}

\section{Distribuição de Todas as Publicações ao Longo do Tempo}

Existem 2749 publicações indexadas em 'modelos computacionais do cérebro humano' (sob as palavras-chave descritas em 'Métodos'). A primeira publicação indexada é de 1969, mas o campo permanece relativamente inexplorado até 1993, quando um boom de estudos tem início, de modo que $95.45 \%$ das publicações (2624 publicações) ocorrem deste ano em diante. Isto nos permite dizer que se trata de um campo novo em franco desenvolvimento.

\section{Delimitação de Temas e Tendências Proeminentes no Campo}

Para que se faça possível uma apresentação consistente dos resultados numéricos e conceituais, novas considerações metodológicas se fazem necessárias; estas não foram incluídas em 'Método' porque, neste caso, optou-se por apresentá-las embutidas de uma forma de resolução à problemática que instauram. 
O princípio maior que guia o uso de softwares de reconhecimento de padrões para a realização de revisões sistemáticas de literatura é a possibilidade de se estabelecer divisões e distribuições temáticas, isto é, de se definir os temas-chave da literatura, desde a análise estatística da ocorrência dos conceitos típicos e das associações que formam no âmbito das publicações indexadas (denominadas clusters temáticos), aliadas a matrizes de correlações entre os próprios clusters, de modo a se superar a dificuldade inerente ao lide manual de estruturas informacionais não-organizadas muito grandes (note-se que, ao longo de todos os campos da ciência, inexistem metasanálise com mais de 1000 estudos compilados).

Para que isto se faça possível, um primeiro procedimento (semiautomatizado) é a definição de tabelas hierárquicas (com seus respectivos valores alinhavados) para os conceitos recorrentes no âmbito dos metadados (incluindo o resumo, palavras-chave e todos os dados bibliográficos secundários). Este processo pode ser denominado semi-automatizado, na medida em que a hierarquia dos metadados se apresenta ordenada em colunas (termos primários, secundários e terciários), de maneira alterável pelo usuário, que 'promove' ou 'demove' conceitos.

Paralelamente, há a possibilidade de se utilizar um ou mais conceitos como elementos-chave para a re-organização hierárquica dos metadados, gerando assim uma quantidade exponencial de ordens, sub-limitadas pelo determinante sob o qual o usuário pretende conceber a organização do campo (i.e. o campo dos modelos computacionais à luz de EEG; o mesmo campo à luz dos estudos em fMRI, etc.). Neste sentido, dir-se-ia que as distribuições temáticas (clusters) podem ser influenciadas pela maneira como o usuário dispõe, entre as diferentes colunas, os descritores que ele compreende como importantes no campo, bem como pelos conceitos que ele promove à condição de tema do estudo. Apenas sendo importante se ter em mente o fato de que o usuário não é capaz de alterar a ordem dentro de cada coluna, ou seja, apenas sendo importante se ter em mente que o procedimento descrito não implica na possibilidade de que os outputs (quantitativamente determinados) sejam arbitrários e não reflitam a estrutura das publicações indexadas.

Caso o usuário não realize nenhuma operação customizada, o software fará a sua interpretação do campo e desta emergirá (através de várias interfaces, diga-se de passagem) o agregamento temático e as possíveis tabelas de correlações. Ainda que o sucesso relativo deste método passivo não seja desprezível, é de se ter em mente que o resultado não é de todo satisfatório, até porque, ao contrário do que pregam os desenvolvedores destas ferramentas, a organização (de base semântica) não é efetivamente semântica, 
conquanto o uso que fazem da linguagem computacional não permite esta capacidade.

Neste sentido, o presente artigo deu o seguinte tratamento à tabela de organização hierárquica dos metadados, no caso composta de 187 conceitos principais e 713 secundários, além de incontáveis terciários: a. sinônimos e conceitos equivalentes (i.e. computação/processamento) foram reduzidos a um só termo, de acordo com o princípio de preservação do mais recorrente; b. conceitos mais 'específicos à prática no campo' existentes na coluna dos conceitos secundários foram promovidos à coluna dos primários, enquanto os conceitos menos relevantes foram demovidos; c. conceitos pouco específicos foram demovidos; d. conceitos que não informavam algo sobre sistema nervoso e metodologia foram demovidos de ambas as colunas principais; e. toda distribuição foi reprocessada sob a égide do conceito de 'computação'. Apenas a título de exemplo, caracterizamos a distribuição conjunta dos tópicos 'aprendizado e memória', ao longo da totalidade dos estudos indexados no tema, na base de dados do PubMed. É de se ter em mente o fato de que este tópico não foi exaustivamente explorado em seguida dado a sua generalidade, o que justamente o faz menos informativo.

\section{Achados Numéricos e Conceituais}

Sob a égide do método descrito acima, destacaremos os achados que mais exibem potencial informacional, isto é, com maior potencial para a revelação de aspectos não-triviais (ou 'ocultos') do campo.

Os modelos computacionais são mais fortemente relacionados à palavra 'aprendizado' (0.14) e 'memória' (presença de 0.9), do que a qualquer outra habilidade cognitiva. Um estudo paradigmático é a modelagem computacional denominada FROST (de: Frontal-StriatalThalamic), que é endereçado à representação e manutenção (por via de loops córtico-talâmicos) dos registros de elementos da percepção espacial, cuja via de integração funcional se resolveria no cortex préfrontal lateral (CPFL) em estágios avançados do processamento (ASHBY; VALENTIN; CASALE, 2005). 'Aprendizado e Memória' têm uma distribuição particularmente difusa, o que aumenta as suas relevâncias relativas, tal como se pode observar abaixo:

Figura 1: Mapa Topológico 2D dos estudos do campo. Todas as áreas emolduradas implicam o conceito de aprendizado ou memória, sendo que as áreas rosadas indicam domínios de agregação de estudos em 'modelos computacionais e aprendizado ou memória'. A distância entre as figuras foi calculada a partir da estatística não-paramétricaKendall tau e reflete o número de permutações necessárias para se chegar dos conceitos chaves de um grupo aos de outros (quantos conceitos precisam ser substituídos para que todos se aglutinem em um só ponto); os dois eixos principais são representados pelos dois principais componentes (conceitos) da totalidade do campo. 


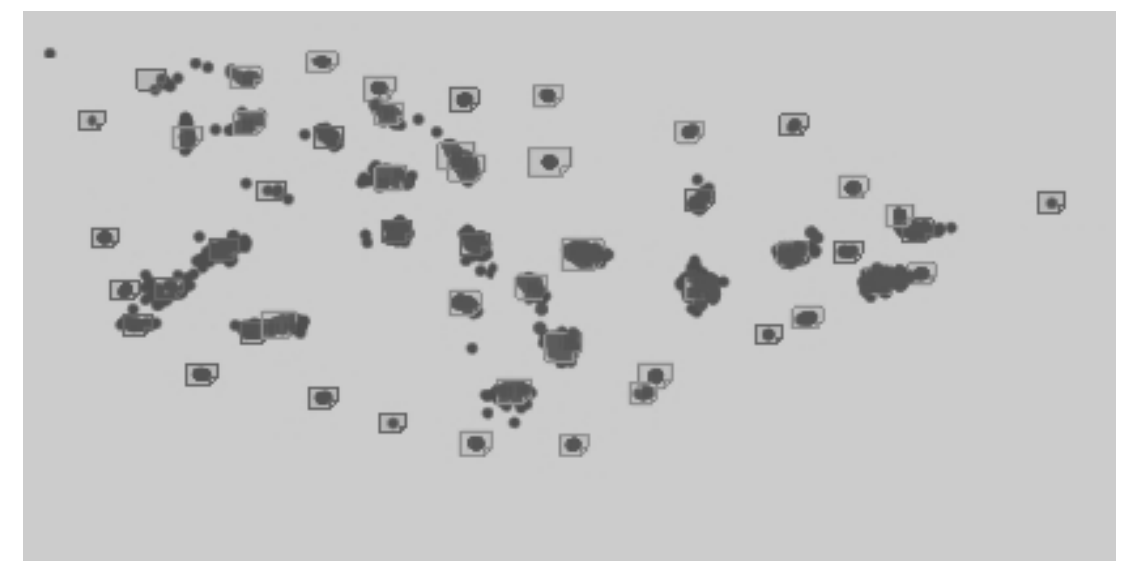

A sensorialidade está mais representada nos modelos computacionais do que a atenção e a linguagem. 'Motor/Áreas motoras' e conceitos derivados estão presentes em $9 \%$ das publicações, enquanto 0 conceito de 'visual/V1/retina' e seus derivados está presente em $8 \%$ destas. Os conceitos de atenção e linguagem têm respectiva penetração de 0.06 e 0.02 . Um exemplo paradigmático de modelo computacional de tipo visual é o estudo de Ariff e colaboradores que modelou a integração entre movimento ocular de tipo sacádico e a dinâmica dos braços para a previsão (computacional) de posições subseqüentes das mãos (ARIFF; DONCHIN; NANAYAKKARA; SHADMEHR, 2002).

No âmbito do uso de modelos computacionais para a modelagem do sistema visual, o foco central do campo revelou-se a modelagem da atenção visual (a correlação entre 'visual' e 'atenção' na tabela de correlações de conceitos indexados sob 'modelos computacionais do cérebro humano' é $r=0.7074)$, ao passo que modelos de atenção auditiva foram menos comuns, sendo a correlação entre 'atenção' e 'auditiva' e seus derivados da ordem de $(r=0.4721)$.

Um estudo paradigmático é a simulação computacional encabeçada pelo pesquisador de Carvalho, da Universidade Federal do Rio de Janeiro, sobre funcionamento das células piramidais do córtex visual para a conjugação dos inputs aferentes (bottom up) desde a via retina-tálamo (no caso, núcleo geniculado) de modo a ativar o modo atencional a informações potencialmente relevantes (de Carvalho e Roitman, 1995) e que conclui que a atenção visual representa uma quebra nos padrões de binding (construção integralizadora de um conjunto de inputs); isto é, que a modelagem ideal da atenção não é dada pela associação crescente de estímulos, mas pela quebra de associações prévias.

Epilepsia, esquizofrenia e Parkinson são as doenças mais proeminentes no campo (com participação de 0.2 cada); Alzheimer é a quarta $(0.1)$, sendo por sua vez mais relacionada à ressonância magnética (MRI) ( $r=0.5435)$ do que à magneto-encefalografia (MEG) $(r=0.2033)$, tomografia por emissão de pósitrons (PET) $(r=0.4718)$ e eletroencefalografia (EEG) $(r=0.1766)$. 'Parkinson' exibe forte correlação com 'Deep Brain Stimulation/DBS', o qual é um método de 
implantação de eletrodos cerebrais para controle neurológico dos sintomas desta doença e algumas outras como epilepsia e depressão maior refratária a tratamentos não invasivos. Isto se justifica dada a importância dos modelos computacionais para a localização das áreas-alvo à implantação destes eletrodos.

Um desenvolvimento paradigmático no campo de estudos da epilepsia é a modelagem computacional de Antel e colaboradores para a localização de focos de displasia cortical (FCD), através da análise de ressonâncias magnéticas, sob o princípio da existência de associações entre estas displasias e a existência de focos epilépticos (ANTEL; COLLINS; BERNASCONI; ANDERMANN; SHINGHAL; KEARNEY; ARNOLD; BERNASCONI,2003).

O córtex pré-frontal está presente em 0.04 dos estudos, enquanto 'substância cinzenta' (presença de 0.02) é mais fortemente correlacionada à análise 'volumétrica' do que a qualquer outro termo $(r=0.8203)$. Isto sugere que sua ocorrência seja massiçamente determinada pelos estudos de imageamento funcional. Um modelo inovador é a análise volumétrica de caráter 'longitudinal' (no sentido em que recebe dados de diferentes períodos da vida do sujeito), relativa à estrutura neuroanatômica de camundongos, e voltada para a compreensão do desenvolvimento pós-natal do Sistema Nervoso Central (SNC), a qual usa como inputs, dados de difusão de tensão (DTI - uma medida da estrutura da substância branca, em função da quantidade de líquido disponível ao longo dos feixes axônicos) (BALOCH; VERMA; HUANG; KHURD; CLARK; YAROWSKY; ABEL; MORI; DAVATZIKOS, 2009).

O 'hipocampo' é área subcortical mais modelada (0.06); o fato de ser a sua presença maior do que a do córtex pré-frontal é sugestiva da dificuldade técnica de se modelar este último. No que se refere àquele, o feixe de fibras mais destacado é o 'CA3', localizado nos colaterais de Shaffer $(r=0.8392)$. Um modelo computacional digno de nota foi proposto por Kunec, Hasselmo e Kopell (2005) para a ativação da circuitaria CA3-giro denteado, através da indução de oscilações nervosas em ritmo teta (4-7 Hertz), característico de atividade biológica e cognitiva. Um aspecto interessante que desponta deste trabalho é que, apesar de ser a capacidade de se memorizar novos conhecimentos relacionada à alta atividade neurológica, dada através de ritmos beta pré-frontais (acima de 12 Hertz), ela se relaciona a ativações em baixas freqüências no hipocampo, o qual é o principal subsistema para a transformação das informações transitórias em memória de longo prazo. Ou seja, destaca-se assim a inexistência de 'um ritmo' da cognição eficiente, em prol da perspectiva de 'uma cadeia de ritmos'.

O neurotransmissor mais presente é a dopamina (0.02), seguida pela acetilcolina (0.01); o termo 'dopaminérgico' possui relações consistentes com 'recompensa' $(r=0.6022)$, apesar de ser um 
conceito pouco relacionado a clusters específicos; 'colinérgico' e derivados estão mais fortemente associado à 'modulador' $(r=0.7562)$, do que 'excitante' (0.6441) e 'inibidor' $(r=0.5568)$, apesar de tão pouco ser um conceito tematicamente concentrado.

Um modelo paradigmático foi proposto por Durstewitz e Seamans (2002), que simularam os efeitos neuromoduladores da liberação de dopamina D-1 no córtex pré-frontal para a memória de trabalho; através deste, eles não apenas apontaram um caminho para a representação do fenômeno, como para a própria cibernética da cognição, que certamente não pode tomar o cérebro como um circuito elétrico qualquer, devendo incorporar os efeitos potenciais de cada neurotransmissor e, ainda mais, da interação entre neurotransmissores para a modelagem computacional.

A correlação entre EEG e fMRI pode ser denominada 'branda' $(r=0.3782)$. Um dos conceitos mais fortemente correlacionado à 'MRI' é 'atlas' $(r=0.8047)$, isto é, sistemas de coordenadas para que se traduza um achado bruto (captação de dados) relativo à atividade cerebral, em um achado específico (áreas cerebrais proeminentes) ao longo desses dados.

Uma inovação conduzida pela pesquisadora Lydia $\mathrm{Ng}$ e colaboradores é o 'Atlas da expressão Anatômica de Genes no Cérebro de Camundongos' (AGEA), que se baseia na base de dados genômicos do instituto Atlas, do qual fazem parte os pesquisadores (NG; BERNARD; LAU; OVERLY; DONG; KUAN; PATHAK; SUNKIN; DANG; BOHLAND; BOKIL; MITRA; PUELLES; HOHMANN; ANDERSON; LEIN; J ONES; MICHAEL HAWRYLYCZ, M., 2009). Este Atlas visa contribuir ao prolífero campo de Atlas 3D do cérebro humano, onde o cânone é - Atlas Talairach. Tal modelo vem sendo cercado de expectativas e promete aumentar a integração entre a genômica e as neurociências. Como conclusão a esta seção, destacamos que estes achados sugerem que a primazia dos modelos computacionais tem muito menos a ver com o 'sentido forte' do que com o 'sentido fraco', dado que os modelos computacionais são muito mais voltados à prática instrumental clínica e diagnóstica do que à representação global ou holística do funcionamento da mente, inteligência ou consciência. Mormente, o conceito de 'modelo computacional do cérebro humano' deve ser primariamente entendido como relativo aos esforços desenvolvidos para aumentar a eficiência de procedimentos invasivos (tal como em \{Modelos computacionais [Parkinson (DBS)] \}) e para dar suporte ao desenvolvimento de novas aplicações, ou seja, é tanto mais um suporte para o desenvolvimento de sistemas de análise computacionais.

\section{Linhas de Força do Campo na Atualidade}

A luz dos achados delimitados acima, o objetivo desta seção -e das próximas- é introduzir as linhas de força que mais intensamente 
permeiam o desenvolvimento do campo na atualidade, em face das quais, faz-se preponderante a questão: 'quais são os aspectos que um modelo computacional do cérebro humano precisa contemplar, para que se possa considerá-lo como potencialmente satisfatório?' Muitas respostas já foram dadas a esta pergunta que, inclusive, pode ser vista como 'tendenciosa', no sentido em que as respostas freqüentemente implicam sistemas de pensamento/linhas filosóficas e não simplesmente conteúdo pontual e objetivo. Por exemplo, é possível se argumentar que os modelos se tornam aceitáveis conforme simulem de maneira a transmitir a um observador a sensação de equivalência entre o funcionamento da máquina e determinados processamentos cognitivos identificados com a mente humana.

Tal corrente se denomina 'funcionalismo' (note-se que esta diverge consideravelmente do 'funcionalismo clássico' de caráter antropológico) e assume que a 'computação', seja ela analógica (contínua) ou digital (discreta, binária) é algo a ser concebido de maneira independente do meio, o qual somente se torna importante para esta problemática conforme se faça objeto de discussões sobre as variáveis técnicas que obliteram 0 atingimento de simulações satisfatórias. Não sendo este o caso, dir-se-ia que o meio (biológico, silício, etc.) é desimportante e que, por exemplo, pensar é a atividade que ocorre em sistemas de processamento que dão como output aquilo que entendemos (socialmente) como o output de um processo de pensamento (para o mais ilustre exemplo, ver: DENNETT, 1978, $1984,1986,1987)$. Uma réplica alegórica e famosa a esta concepção é a de que um computador que nos dá a impressão de pensar como um ser humano é tal qual um sujeito que não fala chinês, isolado em uma sala, comunicando-se em chinês com um interlocutor desconhecido, através de um conjunto de ferramentas tradutoras (SEARLE, 1990).

Saindo desta seara onde a pergunta original se faz tão problemática, destacam-se alguns princípios, definidos com clareza por O'Reilly (1998). Segundo este, os modelos devem apresentar: realismo biológico, sistemas informacionais distribuídos, competição inibitória, propagação bidirecional, aprendizado por erro e aprendizado hebelliano. Por aprendizado hebelliano entende-se o efeito de um neurônio que é ativado por outro, passar a apresentar uma tendência aumentada à co-ativação espontânea (para uma introdução, ver: KANDEL; SCHWARTZ; JESSELL, 2000).

Em consonância com o que sugere o autor, a tendência que desponta na atualidade é de se considerar que parte das networks cerebrais (redes de neurônios intensamente conectadas) opere de modo analógico e, portanto, de maneira consistentemente diversa do modo inteiramente redutível à metáfora do computador digital, delineado 
originalmente por Turing (1950), ao passo que o córtex pré-frontal (CPF) efetivamente opere sob tais princípios.

Em outras palavras: grande parte do cérebro parece ter um comportamento típico de um sistema de processamento contínuo, gradual, em relação ao qual a introdução de novos dados gera alterações relativamente lentas e sustentáveis ao longo do tempo; opostamente, o córtex pré-frontal parece operar princípios descontínuos, voltados à geração de respostas rápidas e inovadoras à presença de dados novos, conduzindo assim a plasticidade comportamental do sistema biológico.

Conforme destacou O'Reilly (1998), isto pode ser explicado da seguinte maneira: a principal função do CPF é manter a atenção/volição/intenção enquanto o indivíduo executa tarefas (por oposição, lesões pré-frontais sempre trazem consigo déficits variados de atenção); a isto que, em essência, refere-se o termo 'executivo'; neste sentido, O CPF recebe aferentes de praticamente todas as outras áreas do cérebro (apesar de não reenviar o mesmo número de eferentes) e modula 'executivamente' o comportamento e o pensamento através da manutenção sustentada das networks envolvidas com uma determinada execução. Para tanto, é imprescindível que controle as redes sustentadas como um interruptor $(1 / 0)$, cuja eficiência mantém relações consistentes com a rapidez com que habilita e desabilita conexões (neste modelo de quadro elétrico da mente). "Enquanto o resto do córtex pode ser caracterizado como um conjunto de dispositivos analógicos, operando informações graduadas e distribuídas, o córtex pré-frontal possui um caráter mais discreto, digital. A manutenção (robusta) da atividade é suportada por uma espécie de bi-estabilidade, o que significa que os neurônios transitam entre dois estados estáveis, ligado e desligado, muito como bytes em um computador" (O'REI LLY, 1998, p. 91).

\section{Revisão dos Achados Mais Relevantes em “Modelos Computacionais do Cérebro Humano em Sentido Forte, 2007- 2009"}

Dando continuidade à proposta da seção anterior, esta seção apresenta um panorama mais objetivo acerca do campo na atualidade, fornecendo achados numéricos e conceituais desde os 'Estudos em Modelos Computacionais do Cérebro Humano em Sentido Forte, 2007-2009'. Estes dados se referem ao conjunto de publicações indexadas nas bases de dados antes mencionadas e que têm como origem grupos de pesquisa de diversos países.

Entre 01/01/07 e 21/03/09 foram indexados 87 artigos nas bases de dados mencionadas em 'Métodos', distribuídos tematicamente de acordo com a tabela a seguir: 


\begin{tabular}{|lr|}
\hline Organização Global & 22 \\
Visual & 11 \\
Modelos de Neurônio & 10 \\
Atenção & 4 \\
Cerebelo & 3 \\
Esquizofrenia & 3 \\
fMRI & 3 \\
Pré-frontal & 3 \\
Senilidade & 3 \\
Aprendizado & 2 \\
Consciência & 2 \\
Linguagem & 2 \\
Tomadas de decisão & 2 \\
Auditivo & 1 \\
Autismo & 1 \\
Epilepsia & 1 \\
Fala & 1 \\
Hipocampo & 1 \\
Medula & 1 \\
Modelo Unificador & 1 \\
Motor & 1 \\
Obsessivo-compulsivo & 1 \\
Perirrinal & 1 \\
Sonhar & 1 \\
Substância branca & 1 \\
Terapia ECS & 1 \\
Tractografia & 1 \\
Trato córtico-espinhal & 1 \\
Trato córtico-pontino & 1 \\
\hline & \\
\hline
\end{tabular}

Figura 2: Tópicos e Número de Estudos em 2007-2009.

Estes achados podem ser referidos à 'Matriz de Correlação entre os Conceitos em Destaque' abaixo, os quais foram extraídos da totalidade dos artigos divididos tematicamente acima, sob os mesmos princípios descritos na legenda da figura 1. A intensidade da cor é correlativa à da correlação.

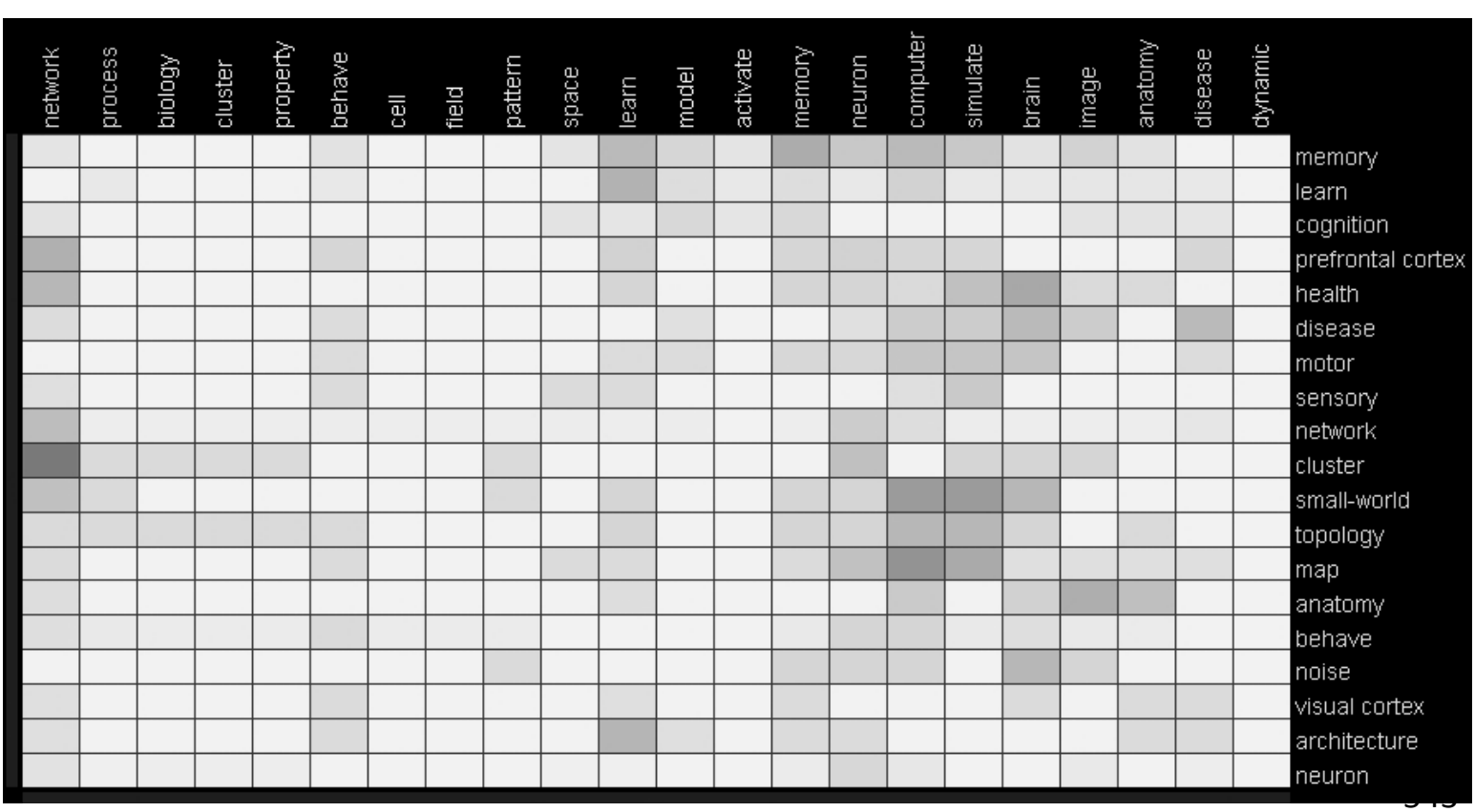


Figura 3: Matriz de Correlação entre os conceitos em destaque nos estudos 2007 2009 (termos em inglês); através desta é possível acompanhar o quanto cada um dos termos-chave do campo se relaciona com os outros.

Esta matriz sugere a seguinte organização primária dos 'Hot topics'. Simulação \{Saúde-Doença [Pré-Frontal (Anatomia)]\}, onde o caráter interno de cada termo reflete sua dependência dos mais externos.

\section{Revisando a 'Organização Global'}

Esta seção introduz conceitos em destaque no âmbito dos artigos tabelados em 'Organização Global', desde os artigos em 'modelos computacionais em sentido forte'. A opção por esta abordagem temática se justifica não apenas em termos quantitativos, mas em função do caráter estratégico da mesma para que se atinja uma visão geral do tema.

Sob o conceito de 'organização global', alinhava-se uma miscelânea de estudos, entre os quais, os mais representativos das concepções atuais em modelagem computacional são os que exploram 'arquiteturas de pequenos mundos' (tais sendo: GRAY; FUNG; ROBINSON, 2009; HAN; LU; WIERCIGROCH; JI; 2009; HUANG;CHENG; SUN, 2007; LIU; LIANG; ZHOU; HE; HAO; SONG; YU; LIU; LIU; JIANG, 2008; PARK; KIM; KIM; KIM; 2008; VAN DEN HEUVEL; STAM; BOERSMA; HULSHOFF POL, 2008; WANG; ZHU; HE; ZANG; CAO; ZHANG, 2009; YIN; WANG; WANG; CHEN, 2008; YU; HUANG; SINGER; NIKOLIC, 2008).

Este conceito traduz a idéia de que o melhor modelo computacional para a simulação do cérebro humano é um em que se façam representadas redes conectivas locais fortemente agregadas (clustered) e conectadas a outros 'pequenos mundos' de mesma natureza ao longo do cérebro, sob a égide do princípio de que a transmissão de impulsos entre quais dois neurônios não pode ser muito demorada e que, portanto, o agregamento das populações locais não pode significar uma distância conectiva muito grande entre quaisquer duas células.

Lembrando que as conexões entre quaisquer duas células não são sempre diretas, este princípio passa a versar sobre o diferente papel/perfil conectivo dos neurônios diversos (e das diversas áreas cerebrais), sob o mote de que a maximização funcional do sistema como um todo não representa a assunção de distribuição conectiva equinanime, mas sim de uma desigualdade afeita aos desafios que se oferecem (se ofereceram no ambiente adaptativo) à espécie. Em outras palavras, a computação que se faz simulada associa-se à modelagem distributiva dos neurônios e conexões de maneira nãolinear, na exata medida em que assume que os princípios computacionais não são unívocos ao longo do cérebro. 
De maneira geral, o tratamento elementar desta conjuntura passa pelo destacamento de algumas células particularmente conectadas (denominadas hubs), as quais justamente permitem que se instale 0 equilíbrio entre agregamento local e distribuição (já que elas são responsáveis por boa parte da função distributiva).

Tradicionalmente, categorizam-se funcionalmente as áreas do cérebro humano em: 'multimodais', relativas ao encontro de neurônios processando estímulos de categorias diversas (i.e. letra e sensação), 'transmodais', relativas ao encontro de neurônios de categorias semelhantes e tipos diversos (i.e. som e imagem) e unimodais, relativas ao encontro de neurônios de categoria e tipos semelhantes; neste sentido, áreas de associação multimodais possuem as conexões mais longas (e obviamente mais importantes para a coordenação de populações neurais diversas), seguidas pelas unimodais e então pelas áreas transmodais do cérebro humano, o que por sua vez significa que componham 'motivos' (motifs) respectivamente menos conectados e funcionalmente diversos, à luz dos mesmos fundamentos determinantes da conectividade dos neurônios particularmente conectados de tipos diversos (para detalhes, ver: BASSETT; BULLMORE; VERCHINSKI; MATTAY; WEI NBERGER; MEYER-LINDENBERG; 2008; VAN DEN HEUVEL; STAM; BOERSMA; HULSHOFF POL, 2008).

Por fim, destaca-se a tendência de se utilizar a concepção à modelagem computacional de distúrbios cerebrais, tais como a esquizofrenia e do déficit de atenção. Em relação àquela, um modelo computacional desta natureza sugeriu que os hubs pré-frontais sejam preteridos por grupos de neurônios particularmente conectados de origem temporal (temporo-inferiores), insulares e amigdalares (BASSETT; BULLMORE; VERCHINSKI; MATTAY; WEINBERGER; MEYER-LINDENBERG, 2008), assim simultaneamente modelando a alta ativação destas áreas e a perfusão pré-frontal diminuída que se observa na esquizofrenia. Em relação ao déficit de atenção, outro modelo de natureza parecida (WANG; ZHU; HE; ZANG; CAO; ZHANG, 2009), sugeriu que a desordem se relacione a um aumento em complexidade local à custa de uma diminuição da complexidade global, sob o mote de diminuição da diferença entre as redes locais (com ênfase na topologia pré-frontal).

\section{Estudos em Andamento e Tendências para o Futuro: a proeminência do 'Blue Brain Project'}

Atualmente, um injustificável paradoxo permeia a inserção do ser humano nos discursos classificatórios das ciências naturais: de um lado, os dados da neuroanatomia, neurofisiologia e genômica comparada sugerem que as diferenças entre o Homo sapiens e os outros primatas são pequenas; de outro, todos os indicadores 
antropológicos e o bom senso exarcebam o caráter absolutamente radical desta ruptura, tornando fatos como o compartilhamento de mais de $95 \%$ de nossos genes com bonobos e outros primatas e a adequabilidade dos modelos animais para a prospecção de vicissitudes potencialmente humanas, pouco relevantes para uma caracterização sensata (adequada ao que se mostra) da especificidade adaptativa da espécie.

É claro que muitos antropólogos e cientistas naturais dirão que as diferenças existentes são oriundas da própria consolidação de um modo de se apropriar das pequenas variações (contexto discursivo no qual se enquadram os diversos modelos que preconizam a formação de uma mente oriunda da cultura). Todavia, sem entrar neste mérito, é de se ter em vista a avassaladora quantidade de estudos demonstrando não apenas a facilitação inata de muitas destas vicissitudes tipicamente humanas (i.e. linguagem), como sua relação com o desenvolvimento de um endofenótipo, cuja perda de conformação precisamente dirime o escopo do traço, tal como se observa na esquizofrenia em relação à perda do potencial de entendimento e vida mental compartilhada, em associação a perdas de assimetria inter-hemisférica e diminuição na conectividade frontotemporal (LAWRIE; BUECHEL; WHALLEY; FRITH; FRISTON, JOHNSTONE, 2002; OKUGAWA; TAMAGAKI; AGARTZ, 2007; SULLIVAN, 1998; TAKAHASHI; SUZUKI; ZHOU; TANINO; HAGINO; NIU, 2006; ZHANG; SHI; YUAN; HAO; YAO; CHEN, 2008).

Possivelmente, quando retomado do futuro, este imbróglio será considerado pelos historiadores da ciência tanto menos como um problema epistemologicamente complexo, afeito a respostas tão diversas quanto qualitativamente irredutíveis (determinadas pelo lugar na escala natureza-cultura em que se situa aquele que a aborda), quanto reflexo de um desconhecimento acerca das propriedades emergentes da estrutura molecular do neocórtex humano, as quais inscrevem o diferencial humano em nível computacional.

É neste sentido que podemos dizer que atualmente se encontra em gestação uma revolução em modelagens computacionais do cérebro humano, apenas rivalizável em importância para o conhecimento da espécie, pelo próprio projeto genoma. Este projeto se denomina Blue Brain Project (http://bluebrain.epfl.ch/) e é uma parceira multicêntrica para a criação da primeira modelagem do cérebro humano inteiro, perspectiva a qual é fundamentalmente mediada pela necessidade de se modelar a estrutura do córtex pré-frontal e dos seus aferentes e eferentes.

Para tanto foi criado o 'Blue Gene' (ALMÁSI; ARCHER; CASTAÑOS; ERWAY; HEIDELBERGER; MARTORELL, 2004), uma arquitetura de super computadores de alta velocidade (até 596 teraFlops), cuja versão final é esperada para 2011 (Blue Gene/Q) e que tem entre os 
seus objetivos maiores 'crackear' o código neural, revelando justamente aquilo que mais nos diferencia dos outros primatas: a robustez da arquitetura neocortical. Atualmente o modelo ainda se baseia em sistemas cognitivos de roedores, mas traz grandes esperanças, bem como já representa o maior feito de toda a história do campo.

Rodando com 8192 processadores ao mesmo tempo, já em 2007 foi possível criar sistemas de resolução em ato das equações matemáticas que regem as trocas de cargas elétricas entre neurônios neocorticais quando da apresentação de estímulos e assim simular o conjunto das computações biológicas do cérebro de roedores em tempo real (mas com um atraso de duas vezes o tempo de realização da atividade in situ). Espera-se ainda para este ano, a simulação em tempo real, vicissitude a qual deve ser facilitada pela incorporação do componente Neuron, um software de simulações para arquiteturas em paralelo notoriamente inovador, que promete aumentar o poder de mapeamento e simulação em tempo real (KING; HILL; GOODMAN; MARKRAM; SCHÜRMANN, 2009).

\section{Conclusão}

O presente artigo trouxe a oportunidade de se conhecer uma série de aspectos quantitativamente fundamentados sobre os modelos computacionais do cérebro humano, da mesma maneira como destacou o caráter estratégico do método utilizado para se chegar a estas conclusões e destacar o caráter potencialmente revolucionário do Blue Brain Project.

Dito isto, é de se ter em vista que a relação tema/método não foi casual e que o ponto a ser ter em vista é que os modelos computacionais (em ambos os sentidos) não precisam ser concebidos como ameaçadores à integridade humana, mas tanto pelo contrário, podem ser vistos como um trampolim para que atinjamos aquilo que de outro modo não poderíamos: a compreensão de nossa peculiaridade filogenética.

Porém, ao contrário de quaisquer modelos atualmente factíveis, o cérebro humano se transforma em tempo real, não apenas por força de rotinas determináveis e implementáveis (i.e. alterações citoarquitetônicas hipocampais, pela ativação de genes relacionados à formação de memórias de longo prazo), como de maneira consideravelmente estocástica (i.e. insultos variados, perdas distribuídas de conectividade, por força do envelhecimento celular), aspecto este que parece despontar como a derradeira fronteira à modelagem computacional pós Blue Brain. A realidade é que processos de desgaste sutil permanecem distantes das modelagens atuais e talvez representem uma fronteira tão importante quanto aquela representada pela consciência. 


\section{Referências Bibliográficas}

ALMÁSI, G.; ARCHER, C.; CASTAÑOS, J. G.; ERWAY, C. C.; HEIDELBERGER, P.; MARTORELL, X. Implementing MPI on the BlueGene/ L Supercomputer. Euro-Par Parallel Processing, p. 833845, Dec. 2004.

ANTEL, S. B.; COLLINS, D. L.; BERNASCONI, N.; ANDERMANN, F.; SHINGHAL, R.; KEARNEY, R. E.; ARNOLD, D. L.; BERNASCONI, A. Automated detection of focal cortical dysplasia lesions using computational models of their MRI characteristics and texture analysis. Neuroimage, v. 19, n. 4, p. 1748-1759, Mar. 2003.

ARIFF, G.; DONCHIN, O.; NANAYAKKARA, T.; SHADMEHR, R. A realtime state predictor in motor control: study of saccadic eye movements during unseen reaching movements. J Neurosci [S.I.], v. 22, n. 17, p. 7721-7729, Sep. 1/2002.

ASHBY, F. G. S. W.; VALENTIN, V. V.; CASALE, M. B. Frost: a distributed neurocomputational model of working memory maintenance. J Cogn Neurosci [S.I.], v. 17, n. 11, p. 1728-1743, Nov 2005.

BALOCH, S.; VERMA, R.; HUANG, H.; KHURD, P.; CLARK, S.; YAROWSKY, P.; ABEL, T.; MORI, S.; DAVATZIKOS, C. Quantification of brain maturation and growth patterns in C57BL/6J mice via computational neuroanatomy of diffusion tensor images. Cereb Cortex [S.I.], v. 19, n. 3, p. 675-687, Mar 2009.

BASSETT, D. S.; BULLMORE, E.; VERCHINSKI, B. A.; MATTAY, V. S.; WEI NBERGER, D. R.; MEYER-LINDENBERG, A. Hierarchical organization of human cortical networks in health and schizophrenia. J Neurosci [S.I.], v. 28, n. 37, p. 9239-9248, Sep 102008.

CHURCHLAND, P. S. Neurophilosophy: toward a unified science of the mind/brain. Cambridge: Mit Press, 1986.

DAY, N. C.; ARNOLD, B. C.; HODKINSON, C. J.; LOVESTONE, S.; BARNES, J. C. P1-357: Integration, search and analysis tools for multidisciplinary clinical and preclinical data to facilitate identification of Alzheimer's disease biomarkers. Alzheimer's and dementia [S.I.], v. 4, n. 4, Supplement 1, p. T323-T323, 2008.

DE CARVALHO, L. A.; ROITMAN, V. L. A computational model for the neurobiological substrates of visual attention. I nt J Biomed Comput [S.I.], v. 38, n. 1, p. 33-45, Jan 1995.

DENNETT, D. Brainstorms: philosophical essays on mind and psychology. Cambridge: Mit press, 1978.

Elbow room: the varieties of free will worth wanting. New York: Clarendon Press, 1984.

Content and consciousness. London: Routledge \& Kegan Paul Books, 1986.

The intentional stance. Cambridge: MIT press, 1987. 
DURSTEWITZ, D.; SEAMANS, J. K. The computational role of dopamine D1 receptors in working memory. Neural Netw [S.I.], v. 15, n. 4-6, p. 561-572, Jun-Jul 2002.

GEYER, C. B.; EDDY, E. M. Identification and characterization of Rhox13, a novel X-linked mouse homeobox gene. Gene [S.I.], V. 423, n. 2, p. 194-200, 2008.

GOLDSTINE, H. H. The computer from Pascal to von Neumann. Princeton: Princeton University Press, 1972.

GRAY, R. T. ; FUNG, C. K. C.; ROBINSON, P. A. Stability of smallworld networks of neural populations. Neurocomputing [S.I.], V. 72, n. 7-9, p. 1565-1574, 2009.

HAN, F.; LU, Q.; WIERCIGROCH, M.; JI, Q. Chaotic burst synchronization in heterogeneous small-world neuronal network with noise. International J ournal of Non-Linear Mechanics [S.I.], V. 44, n. 3, p. 298-303, 2009.

HUANG, C. Y.; CHENG, C. Y.; SUN, C. T. Bridge and brick network motifs: identifying significant building blocks from complex biological systems. Artificial Intelligence in Medicine [S.I.], v. 41, n. 2, p. 117-127, 2007.

JOHNSON-LAIRD, P. N. The computer and the mind. Cambridge: Harvard University Press, 1988.

KANDEL, E.; SCHWARTZ, J. H.; JESSELL, T. M. Principles of neuroscience. New York: McGraw-Hill, 2000.

KING, G.; HILL, S.; GOODMAN, P. H.; MARKRAM, H.; SCHÜRMANN, F. A component-based extension framework for large-scale. Frontieres in Neuroinformatics, 1, 2009.

KOBER, H.; BARRETT, L. F; JOSEPH, J.; BLISS-MOREAU, E.; LINDQUIST, K.; WAGER, T. D. Functional grouping and corticalsubcortical interactions in emotion: a meta-analysis of neuroimaging studies. Neuroimage [S.I.], v. 42, n. 2, p. 998-1031, Aug 152008.

KUNEC, S.; HASSELMO, M. E.; KOPELL, N. Encoding and retrieval in the CA3 region of the hippocampus: a model of theta-phase separation. J Neurophysiol [S.I.], v. 94, n. 1, p. 70-82, Jul 2005.

LAIRD, J. E.; ROSENBLOOM, P. S.; NEWELL, A. Soar: An Architecture for General Intelligence. Artificial Intelligence(33), 1-64, Dec 1986.

LAWRIE, S. M.; BUECHEL, C.; WHALLEY, H. C.; FRITH, C. D.; FRISTON, K. J.; JOHNSTONE, E. C. Reduced frontotemporal functional connectivity in schizophrenia associated with auditory hallucinations. Biological Psychiatry, 51(12), 1008-1011., J un 2002.

LEE, K. H.; SIEGLE, G. J. Common and distinct brain networks underlying explicit emotional evaluation: a meta-analytic study. Soc Cogn Affect Neurosci [S.I.], p. nsp001, March 6, 2009.

LIU, Y.; LIANG, M.; ZHOU, Y.; HE, Y.; HAO, Y.; SONG, M.; YU, C.; LIU, H.; LIU, Z.; JIANG T. Disrupted small-world networks in schizophrenia. Brain [S.I.], v. 131, n. 4, p. 945-961, April 2008. 
MAISOG, J. M.; EINBINDER, E. R.; FLOWERS, D. L.; TURKELTAUB, P. E.; EDEN, G. F. A meta-analysis of functional neuroimaging studies of dyslexia. Ann N Y Acad Sci [S.I.], v. 1145, p. 237-59, Dec 2008.

MARCUS, G. F. The algebraic mind: integrating connectionism and cognitive science. Cambridge: MIT Press, 2001. (Bradford Books).

MIRA, J. M. Symbols versus connections: 50 years of artificial intelligence. Neurocomputing [S.I.], v. 71, n. 4-6, p. 671-680, 2008.

NG, L.; BERNARD, A.; LAU, C.; OVERLY, C. C.; DONG, H-W.; KUAN, C.; PATHAK, S.; SUNKIN, S. M.; DANG, C.; BOHLAND, J. W.; BOKIL, H.; MITRA, P. P.; PUELLES, L.; HOHMANN, J.; ANDERSON, D. J.; LEIN, E. S.; JONES, A. L.; MICHAEL HAWRYLYCZ, M. An anatomic gene expression atlas of the adult mouse brain. Nat Neurosci [S.I.], v. 12, n. 3, p. 356-362, Mar 2009.

OKUGAWA, G.; TAMAGAKI, C.; AGARTZ, I. Frontal and temporal volume size of grey and white matter in patients with schizophrenia: an MRI parcellation study. Eur arch psychiatry clin neurosci; 257: 304-207, Agosto 2007.

O'REILLY, R. C. Six principles for biologically based computational models of cortical cognition. Trends in cognitive sciences [S.I.], v. 2, n. 11, p. 455-462, Nov 1998.

O'REILLY, R.; BRAVER, T.; COHEN, J. A biologically based computational model of working memory. Models of working memory: Mechanisms of active maintenance and executive control [S.I.], p. 375-411, Dec 1999.

O'REILLY, R.; RUDY, J. Computational principles of learning in the neocortex and hippocampus. Development, v. 10, p. 389-397, Sep. 2000.

PARK, C. H., KIM, S. Y.; KIM, Y. H.; KIM, K. Comparison of the small-world topology between anatomical and functional connectivity in the human brain. Physica A: statistical mechanics and its applications, v. 387, n. 23, p. 5958-5962, Oct. 2008.

RICHLAN, F.; KRONBICHLER, M.; WIMMER, H. Functional abnormalities in the dyslexic brain: a quantitative meta-analysis of neuroimaging studies. Human brain mapp [S.I.], Mar 132009.

SACKS, $O$. 0 homem que confundiu sua mulher com um chapéu. São Paulo: Companhia das Letras, 1997.

SEARLE, J. R. Is the brain a digital computer? Proceedings and addresses of the american philosophical association [S.I.], $\mathrm{V}$. 64, n. 3, p. 21-37, Jan. 1990.

SMOLENSKY, $\mathrm{P}$. On the proper treatment of connectionism. Behavioral and brain sciences [S.I.], v. 11, p. 1-74, May 1988.

SULLIVAN, E. V. A profile of cortical gray matter volume deficits characteristic of schizophrenia. Cereb cortex, v. 8, n. 2, 117-124, Sept 1998.

TAKAHASHI, T.; SUZUKI, M.; ZHOU, S. Y.; TANINO, R.; HAGINO, H.; 
NIU, L. Temporal lobe gray matter in schizophrenia spectrum: a volumetric MRI study of the fusiform gyrus, parahippocampal gyrus, and middle and inferior temporal gyri. Schizophrenia research, $v$. 87, n. 1-3, 116-126, Oct. 2006.

THOMPSON, P. M.; APOSTOLOVA L. G. Computational anatomical methods as applied to ageing and dementia. Br J Radiol, v. 80, n. 2, S78-91, 2007.

TURING, A. Computing machinery and intelligence. Mind [S.I.], V. 59 , p. 433-460, 1950.

VAN DEN HEUVEL, M. P.; STAM, C. J.; BOERSMA, M.; HULSHOFF POL, $\mathrm{H}$. E. Small-world and scale-free organization of voxel-based restingstate functional connectivity in the human brain. Neuroimage [S.I.], v. 43, n. 3, p. 528-539, Nov. 2008.

VON NEUMANN, J. First draft of a report on the EDVAC. University of Pennsylvania. Pennsylvania, p.47. 1945

WAGER, T. D.; LINDQUIST, M.; KAPLAN, L. Meta-analysis of functional neuroimaging data: current and future directions. Soc Cogn Affect Neurosci [S.I.], v. 2, n. 2, p. 150-158, J une 2007. WANG, L.; ZHU, C.; HE, Y.; ZANG, Y.; CAO, Q.; ZHANG, H. Altered small-world brain functional networks in children with attentiondeficit/hyperactivity disorder. Hum Brain Mapp [S.I.], v. 30, n. 2, p. 638-49, Feb 2009.

WITT, S. T.; LAIRD, A. R.; MEYERAND, M. E. Functional neuroimaging correlates of finger-tapping task variations: an ALE meta-analysis. Neuroimage [S.I.], v. 42, n. 1, p. 343-56, Aug 2008. YANG, Y.; AKERS, L.; KLOSE, T.; BARCELON YANG, C. Text mining and visualization tools - Impressions of emerging capabilities. World Patent Information [S.I.], v. 30, n. 4, p. 280-293, 2008.

YIN, C. Y.; WANG, B. H.; WANG, W. X.; CHEN, G. R. Geographical effect on small-world network synchronization. Phys Rev E Stat Nonlin Soft Matter Phys [S.I.], v. 77, n. 2 Pt 2, p. 27-102, Feb. 2008.

YU, S.;HUANG, D.; SINGER, W.; E NIKOLIC, D. A small world of neuronal synchrony. Cereb cortex [S.I.], v. 18, n. 12, p. 28912901, Dec 2008.

ZHANG, Z.; SHI, J.; YUAN, Y.; HAO, G.; YAO, Z.; CHEN, $\mathrm{N}$. Relationship of auditory verbal hallucinations with cerebral asymmetry in patients with schizophrenia: An event-related fMRI study. Journal of Psychiatric Research, 42(6), 477-486, May. 2008. 


\section{Endereço para correspondência}

\section{Álvaro Machado Dias}

Laboratório de Neuroimagem LIM21, Instituto de Psquiatria da Universidade de São Paulo (IPq-FMUSP), R. Dr. Ovidio Pires Campos s/n, Cerqueira Cesar, CEP 05403010, São Paulo - SP, Brasil

Endereço eletrônico: alvaromd@usp.br

Recebido em: 27/10/2009

Aceito para publicação em: 07/01/2010

Acompanhamento do processo editorial: Adriana Benevides Soares

\section{Notas}

* Psicólogo e Mestre em Psicologia pela Universidade de São Paulo - USP; Bolsista CNPQ e FAPESP, Doutor em Neurociências e Comportamento pelo Instituto de Psicologia da Universidade de São Paulo - IP-NEC-USP. 